\title{
Planning Education and Inter-cultural Collaboration: Awareness, Innovation, Reflection and Preparation for Practice
}

\author{
Andrew Butt, Rangajeewa Ratnayake, Trevor Budge \\ La Trobe University, Australia
}

A.Butt@latrobe.edu.au,R.Ratnayake@latrobe.edu.auT.Budge@latrobe.edu.au

\begin{abstract}
Inter-cultural awareness and the capacity for cross-cultural collaboration is a fundamental contemporary element of planning practice, and increasingly of a planning career. The development among planning students of cultural awareness and reflection on practice is crucial to their future roles as planning practitioners in multi-cultural communities and in a globalised body of research and practice. Moreover, students are aware of the increasing global flows of contemporary careers, with students seeking work in international settings. Developing inter-cultural awareness and capacity for reflective practice is, however, challenging at a personal, professional and educational level. This paper describes and reflects on a series of innovative collaborative fieldwork and studio visits of planning students on exchange between La Trobe University Australia and the University of Moratuwa in Sri Lanka over the last three years. It will utilise reflective assessment and observation centred on these visits to explore the way in which students from both countries enter the process of inter-cultural learning and the way in which such transformative experience effects perceptions of planning practice among those entering the profession. Key findings relate to the development of a global mindset and the varied success in the navigation of inter-cultural challenges as a developing professional.
\end{abstract}

\section{Introduction}

The internationalization of the planning education curriculum, and indeed the broader push for globally focused experiences and literacies in higher education generally, has come to be seen as a central means to develop culturally competent professionals able to operate in diverse communities and environments. Moreover, students appear to be increasingly demanding programmes of study that offer greater scope for exploring broader international career possibilities (Goldstein et al, 2006). Specifically in planning education, the increasing relevance of 'cultural literacy' for graduates emerges from the growing awareness of immersion in a professional environment where diversity and reflexive approaches to practice are valued. However these values are often difficult to articulate or replicate within a classroom setting. The literature reviewed in this paper suggests that there is a growing emphasis on internationalization of curriculum and demand for the provision of field experience as a response to this need. While the growth in international intake in Australian universities offers some opportunities in this respect (although perhaps not distinctly in Australian planning programs), it is overseas study through a diverse range of programs and opportunities that is often seen as offering an increasingly popular and realistic approach to broadening and strengthening student experience.

This paper reflects specifically on and explores the experiences, challenges and outcomes of a structured ongoing collaborative planning educational initiative between planning staff and students from the planning program at La Trobe University in Australia and the University of Moratuwa in Sri Lanka. This initiative has included staff exchanges, small group student exchanges, research collaboration, large-group student field studies and the development of a shared 
post-graduate degree allowing part completion at either institution.

The results and reflections of these initiatives and activities show that the opportunities for reflective, international practice is highly valued by students in both countries - both as a means of (re)considering the position of planning professionals and practice at home, and as a consequence of the high levels of planned international careers among graduates.

The paper discusses the context within which the process of engagement took place - as an extension of the long running Planning Institute of Australia (PIA) post-tsunami projects in Sri Lanka, the background to this collaborative initiative, the process and details of the student's collaborative exercise, the perceptions of staff and students at both institutions and an appraisal of the critical learning outcomes of engagement, encounter and critical reflexivity in terms of cultural literacies and planning exchange; specifically the degree to which the experience of overseas planning project study has resulted in a capacity for students to engage with other situations, reflect on their encounter with these circumstances and modes of learning, and the degree to which an ability to be reflexive to cultural circumstances is developed (if at all). Finally, it offers recommendations to address the limitations and barriers of these exercises with a view to improving future international collaborative projects.

\section{International Planning Education}

The internationalisation (or globalization) of higher education has emerged as a highly relevant topic in course and subject design and in student demand. This process has been particularly evident in planning education. We contend that the need for a multi-cultural or cross cultural understanding of planning is highly relevant to developing meaningful reflective planning practice in the local context, and also in preparing graduates with a global outlook. Pedagogical imperatives aside, many students demonstrate a strong personal and professional interest in international study opportunities and the possibilities of international careers in developed and developing world situations. Increasingly, the development of international engagement opportunities features in higher education in Australia and elsewhere, most strongly in relation to the attraction of international (fee paying) students, but also through the recognition of the relevance of international research linkages, student exchanges and student mobility. Harman (2005) describes the emergence of an internationalisation imperative within universities, but also as an aim of government in Australia and elsewhere - dominated by the aims of developing an international education 'market'. In reviewing policy, Harman (2005) reveals mixed results for the broader process of 'internationalisation in its various forms, but despite this the important pedagogical benefits of student encounter and exchange are reported positively.

Importantly, international perspectives in curriculum emerge as not only desirable, but crucial from both a student and curriculum perspective. Healey (2012) outlines the critical issues in developing an internationalised approach planning, specifically in recognising many of the transferable and universal ideas of planning compared with those that are locally contingent. This suggests that students need to understand international settings, but also to recognises similarities and differences between planning in different places. Absolum and Vadura (2006) recognise that "simply adding international content is not enough" (p332) in their study of students at the University of South Australia. Students consider interaction to be a critical part of their education. For planning schools, this offers the opportunity to utilise international professional and disciplinary commonalities to develop interactions that challenge cultural assumptions.

A trend towards increasingly international planning curricula is identified as a product of this expressed need and awareness from staff and students. Ali and Doan (2006), for example, identify an emerging trend towards specific strategies for internationalisation in their survey of planning curricula in the United States. Goldstein et al (2005) suggest a globalisation in the planning academy, and 
describe a multi-national collaborative project where, despite some limits to 'direct relevance' of the experience, the development of culturally aware professionals was enhanced. Dandekar (2009) offers support for international encounter and collaboration in smaller planning schools to overcome what she suggests are more limited opportunities for international curriculum and engagement.

In Australia, the value of an internationalised planning curriculum is identified as critical to preparing practitioners for a globalised profession. The recently revised and adopted Accreditation Policy for Recognition of Urban and Regional Planning Qualifications (PIA, 2010) by the Planning Institute of Australia (PIA) identifies a capacity to work in diverse communities as a critical professional competency. In their review of Australian planning education, Gurran et al (2008) broaden this to notions of adapting to 'unfamiliar' settings and appreciating international concerns.

\section{Practice and Engagement in an International Setting}

The use of project 'practicum' and other fieldwork exercises in planning education have long been recognised and advocated as critical elements (along with work experience) of incorporating experiential learning and developing professional knowledge and understanding (Silk \&Bowlby (1981), Kotval (2003), Jones et al (2008) and Jones et al (2009)). Likewise the use of international fieldwork has become common. Moreover, the increased international linkages, and factors such as the relative affordability of international travel offer possibilities for increased use of such programs. Yigitcanlar et al (2009) detailed one such programme in Malaysia at the 2009 Australia and New Zealand Association of Planning Schools (ANZAPS) conference. They identified benefits through exposure to another planning culture and broader insight to cultural difference amongst participants. They also postulated the need for students to address the barriers presented by this program; however they suggested that these in themselves offer a learning opportunity.

\section{Globalising Education and International Experience}

Such international processes do of course present challenges and limitations. The actual pedagogical results of overseas visits are often revealed as less tangible than initial expectations. Goldstein et al (2005) describe structural and pedagogical barriers in education models and cultures. Auffrey and Romanos (2001) suggest success in developing a global awareness among students, albeit inferred through unanticipated exchange, and in the face of difficulty in negotiating a program within another culture. In this respect the actual professional competencies learnt were subsumed by the cultural competencies. Likewise, Yigitcanlar et al (2009) describe a process of learning through exchange, even where logistical limitations to the program where apparent. Importantly, however, commonalities in planning education and professional practice offer a means to build mutual exchange through common appreciation of the core concerns of planning (Abramson, 2005). Those with a generic planning education can see planning as a commonality in otherwise unfamiliar collaborative environments. Consequently, the process of learning within an international context can be viewed as both a learning process shaped around the subject and activities, and one where an implied learning is gained through a transformed perspective on professional practice. That process is played out against the realities of the socio, cultural and political environment within which planning is undertaken.

\section{Cross Cultural Encounters and Transformative Learning}

Notions of transformative learning - that is the process of reflecting on assumptions and expectations to inform practice - have significant relevance in professional development for planners; both professionals and students. Forester (1998) outlines the ways in which dialogue and interaction provide a basis for such transformation in planning practice, offering a process of learning through exchange and consequent reflection. However the idea of learning through practice and the consequent 
transformative process is usually understood as the accumulation of knowledge and as the product of long periods of contact and reflection. In contrast, the possibilities of transformation presented through international inter-cultural immersion and contact appear to offer a means to a more immediate and confronting response. In discussing the US example, Montuori and Fahim (2004) suggest that such encounters 'reveal' the invisibility of cultural assumptions and draw out creative skills in managing this revelation. Those immersed in such experiences find that they must adjust or at least accommodate perspectives that may confront them in a relatively short time period if they are to operate effectively both within themselves and in their dealings with others. From within multi-cultural Australia the chance for such encounters is evident,even if only superficially. Moreover, the increasing mobility of young Australians offers such encounters elsewhere - albeit often through the 'tourist gaze'. The possibilities of transformation through professional encounter remain a more elusive but a most potent experience for many planning students.

This approach of realisation through immersion underpins part of the philosophy of the exchange of planning students and staff that has been undertaken between La Trobe University and the University of Moratuwa over the past two years. The most recent exercise saw eleven La Trobe planning students and two staff visit Sri Lanka to undertake project-planning activities with Sri Lankan planning practitioners and students in March 2011. Reflections and assessment of the way in which this and other previous fieldwork visits offered an international experience to planning education for students in both settings, while revealing hitherto unexplored assumptions about Australian teaching and learning, and planning practice, are detailed below:

\section{The Implications of Internationalised Experience}

The following analysis relates to considerations of structured post-travel feedback (Budge and Butt, 2010) to explore the perceptions of students of the experiences of international study and fieldwork, crosscultural encounters and personal transformative reflection. Feedback forms have been filled by twenty-one Sri Lankan planning students of University of Moratuwa who have participated in planning projects in Australia in 2009 and 2010 and twenty five Latrobe planning students who undertook project planning activities in Sri Lanka in 2010 and 2011. This is largely considered in the context of wider reflections by the authors of the ongoing process of exchange. These factors, as described above, form the basis of the rationale for increased internationalisation of the planning curriculum, with consequent outcomes for future professionals. Overall, student feedback has been positive in the various exchange and study visit programs. Challenges have been noted, variously relating to dilemmas in understanding different modes of learning and professional practice, and more obvious issues with navigating different cultural settings on a daily basis. Despite apprehension, most students from both institutions have noted a positive experience, although often this has most strongly emerged some time after their return. For example, most Sri Lankan participants reported a relatively high level of satisfaction with their field work and study program at the LTU. Their satisfaction derived from their practical program, language skills development, intellectual growth, intercultural and interpersonal skills, quality services, and effective learning support systems. Most participants described lecturers as being professional, patient, helpful, empathetic, competent, well organized, friendly, and understanding. Students were deeply impressed with the flat rather than hierarchical mode of teacher-student classroom interactions. According to one Moratuwa Student who visited La Trobe in 2010:

"LTU staff showed acted as guardians, and arranged all the facilities and helping undergraduates from $S L$ to expose into new learning experiences."

The identified implications of international study (and staff exchange) experiences in this instance most readily relate to cross-cultural awareness, the negotiating of different cultures of learning and practice and the capacity of 
this to offer reflection on practice (and personal development) at home.

\section{Negotiating Cultures of Learning and Practice}

This was perhaps the most challenging aspect of the experience for many participants from both institutions. Student participants generally express some knowledge of differences in approaches to teaching and learning, institutional settings and organisational situations prior to travel, yet these expectations (including those formed from briefings and pre-tour discussions) are often insufficient to actually prepare for differences in the modes of learning and practice experienced.

One La Trobe student visiting Sri Lanka in 2010 initially observed that this was:

"The Exciting opportunity to study and work in a completely different environment and with an overwhelming desire to learn as much as possible to assist"

However, after the visit it was observed that they had "... gained an appreciation of the bureaucratic and social barriers to planning in a developing country" and that students "...need to keep a sense of humour and remember that you may benefit more once home than on the actual program". This also demonstrates the tensions between preparation and immersion, and indicates opportunities and risks from short-term visits.

In the case of Australia and Sri Lanka, differences in models of teaching and practice include interactions between staff and students, interactions between students, the role of hierarchies within the university setting and within project groups that were formed. Students also observed differences in the procedural approaches to communications with agencies and communities. For example, typically Australian practice includes less formalised classroom structures and linkages within and beyond the project team, while Sri Lankan approaches include a stronger reliance on discussion and consensus within well understood structures, while processes such as information gathering for projects rely on highly formalised linkages and networks. Similarly, differences in classroom expectations were noted, for example in Sri Lanka a 'quiet note-taker' is often considered an ideal student, whereas in Australia an outspoken student is often valued by peers and teaching staff.

These pedagogical differences have been observed by students, with Sri Lankan students in Australia recognising a need to not only adapt to models of learning and practice with less reliance on the mastery of social science methods and data collection, but also to elements of academic expectations and even language barriers ${ }^{1}$ that prevented Sri Lankan students from effectively communicating with lecturers and Australian students, listening to discussions, and with socializing with domestic residents. Likewise, Australian students in Sri Lanka have observed the need to consider different procedural emphases in project work, and issues with spoken English, as well as teaching styles have been observed. One La Trobe student in Sri Lanka 2010 observed issues of process and the social practices of planning as being a crucial lesson from the program:

"I have gained an appreciation of the bureaucratic and social barriers to planning in a developing country."

Consequently, the approaches to studying in another setting and learning through a field setting are challenging for students from both institutions. Students considered these differences to be perhaps most challenging for learning tangible elements of practice (regulatory details etc), yet the need to be adaptive and reflexive in this environment has been stated by participant students as a most useful outcome.

The implications of this dilemma point to the need for clearly developed intercultural competencies of staff and group leaders/facilitators, but also suggest that a strong focus on planning method and practice (through field studies and practicum) may have some limits in the transferability of approaches and methods. Despite this, exposure to other ways of learning and assumptions about practice are in themselves fundamental to the international experience, 
and perhaps more long lasting than exposure to techniques and context in the field or the classroom.

\section{Developing Cultural Literacy}

The idea of cultural encounter and international experience as a model for developing cultural literacy is important, but comes with significant challenges for a 'study abroad' program. Contact in itself cannot be seen to automatically offer this outcome and may, in fact simply reinforce stereotypes of cultural settings, rather than offering a deeper understanding of difference (Otten, 2006).

Student experiences to date indicate a mixed experience in this regard. Undoubtedly students who have travelled from either country have a strong sense that the experience has allowed the development of awareness and sensitivity to cultural difference - yet the process also offers participants perspectives that may reinforce more stereotypical views of cultural norms. Differences in modes of work practice and learning techniques, as well experiences in the civic and social realm are most evident in responses. The immediacy of a study tour is a challenging environment to overcome more shallow perspectives of difference and to develop a well-formed and appropriately critical and reflective understanding of another culture. Students from both universities have commented on the brevity of the visits and the need for preparation - however it may be that such experiences can only ever be part of a personal and professional pathway to crosscultural understandings.

Developing this awareness is highly valued by students, not just by educators. Student participants in the international programs undertaken to date have expressed this as an important aspect of what they anticipate, and ultimately learn from the program. However, reflections on the programs suggest that for some, this development is not fully experienced as personally relevant. Cultureshock may not sufficiently give way to a developing cultural literacy for some individual students within the often short scope of these programs.

\section{Developing Awareness, Reflection and Transformation}

The personal consequences of international experience, through reflection and cultural awareness are seen as perhaps the most broadly useful outcomes of such internationalisation. Within the literature, the scope to utilise this in 'home' practice is seen as separate to the more specific development of 'cultural literacy'. Indeed such transformation does not presuppose future professional inter-cultural contact, but rather asserts that adaptive and reflexive behaviours may form when confronted with the 'other' as social and professional practice.

In this regard, the experience of study and professional contact between Australian and Sri Lankan students has offered a means for students to envisage changes in their 'home' approaches to planning education and practice - and this notion has been strongly borne out in discussions and feedback. Students have stated that they can see applicable (and less applicable) alternative models of planning in areas such as transport, housing and community engagement that offer reflection of existing assumptions and pre-existing approaches. Many Sri Lankan students said that their biggest achievements were their problem identification and problem solving skills in a completely different set up that transformed their learning experiences, for example, when it was anticipated that complex data were needed to frame problems and make strategies for urban issues.

After the field work study in Australia, one University of Moratuwa student realized that she had changed a great deal. She had learned that multiple methods (secondary data, public participation, observations and interviews) can also be utilised to frame urban issues and make design strategies.

"This program improved my knowledge in urban planning, especially the way they practice urban planning using different methods for example, public participation as a tool for data gathering and formulating solutions."

Moreover, students have asserted that such reflection has also occurred at a personal level 
in relation to engagement in the public realm and with unfamiliar (and uncomfortable) situations. Specific student observations have related to the difficulties in overcoming cultural expectations within the length of exchange, although the ongoing nature of the international relationship will ideally offer many students the chance to experience the student and staff exchanges (from different situations) a number of times during their course of studies at the respective institutions. Indeed, some Sri Lankan students reflected that the length of the study program was not enough to understand the different planning system and culture. As a 4th year Moratuwa student mentioned,

"The length of the program is definitely not enough. The amount of time for us to get exposed to the culture was not enough. It felt as if we did everything in a rush."

Most Sri Lankan students valued the group discussions and group activities, where they could interact with local students. They saw this as an opportunity to improve their English language skills, to enhance their cultural understandings through intercultural encounters and to broaden the understanding of contextual urban issues. Some SL students, having experienced difficulties making friends with local students, saw group discussions as opportunities to make new friends anddevelop communication skills. As a Moratuwa staff member pointed out,

"Be prepared for a total different exposure and please note that due to the communication barrier, many will be little reluctant in coming forward, but once you work in groups and feel comfortable about the language, the things you can learn are just simply brilliant."

Any process of transformation is, again, fraught, as underlying assumptions about other cultural settings are unlikely to be wholly dismantled over a short study tour. The ongoing two-way contact we have developed may offer some scope for longer-term dialogue in each 'home' setting.

Furthermore this research confirms early research findings that Asian students in English speaking countries had difficulty making friends with domestic students
(Newall\&Daldy, 2004; Ward, 2001; Ward \&Masgoret). Students highlighted this point and said that this difficulty might lie in the different ways of thinking and behavior and in cultural differences that had become barriers to communication. One Moratuwa student observed that this situation might be minimised if there is an orientation program for both Moratuwa and La Trobe students to know about cultural expectations and behaviours, ways of approaching a conversation, common topics that could encourage such communication, and general approaches to social communication:

"There must be a orientation programme for the students when in Australia with theintroduction of the foreign friends to know about their culture family and all the information about them to create a friendly environment with them."

In general, however experiences where positive. As one La Trobe student in Sri Lanka observed, "...we just have to be prepared for things not to go to plan...".

\section{Lessons for continuing linkages and international planning education}

Reflections on this program are positive, but the longer-term opportunity to enable and develop culturally literate professionals is yet to be seen. While these are personal subjective comments from students the staff at both universities are now in position to make reflective observations on the students who have experienced exchange programs. In terms of La Trobe University eighteen students have now undertaken studies in Sri Lanka in two structured study visits. Six students have chosen to participate twice. Staff have accompanied students on both study tours. In total, 22 students from Moratuwa have visited Australia over two visits, once with staff. This has included students who have also been present as tutors after graduation. These experiences have enabled observations at first hand as to how students have reacted and responded to new cultural and learning settings. Four observations stand out.

i. There is a growing level of maturity and self-confidence by all who have 
participated - but it is highly variable with some students displaying profound and very visible changes even in a relatively short times. Other students display changes that are less noticeable but are apparent on reflection. Some students have observed that having to respond and function in a different and often strange environment has been useful when they subsequently found themselves in unfamiliar territory in subsequent projects and practice particularly in relation to problem framing and solving skills - where a transformation in the conception of planning issues has been noted by students from both institutions.

ii. This circumstance engendered a new sense of responsibility in students which they have acknowledged in ongoing student group contact regarding planning issues. Australian planning students found that they were being seen as representative of Australia's planning students and in a sense the planning profession. Some found this daunting, as there was often an expectation from some Sri Lankan students that as they were from a developed country that they would be able to represent a more 'sophisticated' and learned view of planning.

iii. Some students from both institutions have developed a strong sense of purpose in relation to internationalization. Partly through a self-interest in looking to ultimately work in developing countries (for Australian students) or scope to work in planning systems elsewhere (for Sri Lankan students) but moreover through a strong recognition of the comparative issues of practice and culture, and the possibilities of ongoing social and professional exchange. The study visits have accelerated some student's comprehension, understanding and their passion for being part of a development agenda.

iv. The awareness among students of the cultural challenges to learning in another environment. Cultures of social practice and particularly the requirements of academic literacy, which requires "disciplinary enculturation," specialized knowledge, and a profound understanding of norms and conventions that are embedded in cultural values and beliefs" (Casanave, 2002: 27) have proven a key challenge to many students, one that requires further consideration in the design of exchanges, where the motivation is at once to expose students to new ways of learning, while recognising requirements of their home setting.

\section{Conclusions}

Some limitations remain in our understanding of the capacity of the program to deliver on critical elements of an internationalisation agenda. Firstly, there is a need to better understand the impacts and benefits for the non-travelling student group - those who experience the exchange from their home setting. As with international student intakes in general, it may be that this group is only marginally engaged in the process of encounter and exchange. Secondly, there is a need to consider the longitudinal benefits of international studies - to explore the transition into professional practice and consider the ways in which these experiences factor into ongoing professional awareness and development. To date feedback has been encouraging. The long-term nature of the relationship between the two universities means that the observations about weaknesses and limitations can be tackled as part of future exchanges and programs. Both universities are now open to the opportunities to learn mutually and to reflect on the capacity of what is still an evolving and developing relationship. The implementation of a joint postgraduate course in 2012 and the prospect of students undertaking a full year on exchange in the partner university in the second year of the course in 2013 is both a daunting and exciting prospect which will give a much more solid base to the learning from this ongoing exchange program. 


\section{References}

Abramson (2005) 'The" Studio Abroad" as a Mode of Transcultural Engagement in Urban Planning' Journal of Planning Education and Research 25(1)

Absalom, M. \& Vadura, K. (2006) 'Student Perceptions of Internationalization of the Curriculum: An Australian case study' Arts and Humanities in Higher Education 5(3) pp317-334

Ali, A. \& Doan, P (2006) 'A Survey of Undergraduate Course Syllabi and a Hybrid Course on Global Urban Topics' Journal of Planning Education and Research 26; pp222-236

Amirahmadi, H. (1993) ‘Globalization and Planning Education’ Environment and Planning B 20(5) pp537555

Auffrey, C, and Romanos. M (2001) 'Educating the educators: Global dimensions of collaborative fieldwork in an urban region of Southeast Asia'. Journal of Planning Education and Research 20 (3): 353-64

Budge, T (2007b) Report to PIA on Implementation of an Education and Training Program as part of the PIA Tsunami project unpublished

Budge, T. (2007a) 'New Approaches to Capacity Building Models for Asian Planners: The Tsunami Reconstruction Partnership between the Institute of Town Planners Sri Lanka and the Planning Institute of Australia', paper presented at the Asian Planning Schools Association Congress Colombo Sri Lanka 26-27 August 2007

Budge, T., Butt, A. and Ratnayake, R. (2009) 'Cross Cultural Learning from the Tsunami: Professional Planners from Australia and Sri Lanka', Bhumi: The Research Journal of the University of Moratuwa Towns and Country Planning Program 1(1)

Budge, T and Butt, A (2010) Planning for the new millennium: students in 'Serendip', Paper Presented at ANZAPS 2010, Christchurch, NZ

Casanave, C. P. (2002). Writing games: Multicultural case studies of academic literacy practices in higher education. Mahwah, NJ: Lawrence Erlbaum

Dandekar. H (2009) 'Commentary: A Multiuniversity Planning Studio at the World Planning Congress : An Opportunity for International Planning Education', Journal of Planning Education and Research 28(3) pp382-390

Forester, J (2008) The deliberative practitioner: encouraging participatory planning processes, MIT Press, USA

Friedmann, J. (1996) 'The core curriculum in planning revisited' Journal of Planning Education and Research 15 (2): 89-104

Goldstein, H. Bollens, S., Feser E. and Silver, C. (2006) 'An Experiment in the Internationalization of Planning Education: The NEURUS Program', Journal of Planning Education and Research 25(4) pp349-363

Gurren, N., Norman, B. \& Glesson, B. (2008) Planning Education Discussion Paper, Prepared for the Planning Institute of Australia, Canberra

Hamza (2009) 'International Experience An Opportunity for Professional Development in Higher Education', Journal of Studies in International Education, 14(1)

Harman, G. (2005) 'Internationalization of Australian Higher Education: A Critical Review of Literature and Research', in Ninnes, P and Hellstén, M. (eds.), Internationalizing Higher Education, Springer pp119-140. 
Hoffman, M. (2006) Postcard from Sri Lanka, Planning Institute of Australia (at www.planning.org.au)

Jones, M., Coiacetto, E., Jackson, J., Coote, M., Steele, W., Budge, T. \& Gall, S. (2009) 'Generating academic standards and assessment practices in work integrated learning: a case study from urban and regional planning', Asia-Pacific Journal of Cooperative Education, 10(3): 203-215.

Jones, M., Jackson, J.T., Coiacetto, E., Budge, T., Coote, M., Steele, W., Gall, S. \& Kennedy, M. (2009) Generating Academic Standards in Planning Practice Education: Final report to the Australian Learning and Teaching Council

Kotval, Z (2003) 'Teaching experiential learning in the urban planning curriculum' Journal of Geography in Higher Education 27(3) pp297-303

Montuori, A. \& Fahim, U. (2004) 'Cross-cultural encounter as an opportunity for personal growth' Journal of Humanistic Psychology. 44(2) pp243-263.

Otten, M (2003) 'Intercultural Learning and Diversity in Higher Education' Journal of Studies in International Education 7(1) pp12-26

PIA (2010) Education Policy for Recognition of Australian Planning Qualifications (Urban and Regional Planning Chapter), Planning Institute of Australia, Canberra

Reeves, D. (2005) Planning for Diversity: Policy and Planning in a World of Difference, (Routledge: London)

Silk, J. and Bowlby, S. (1981) 'The use of project work in undergraduate geography teaching' Journal of Geography in Higher Education, 5(2) pp155-162

Taylor (2008) 'Transformative Learning Theory' in Merriam, S (ed) Third Update on Adult Learning Theory: New Directions for Adult and Continuing Education, No. 119, Jossey-Bass, San Francisco, USA

Van Horen, B. Leaf \& Pinnawala (2004) 'Localizing a Global Discipline: Designing New Planning Programs in Sri Lanka', Journal of Planning Education and Research, 23 pp. 255-268

Ward, C., Bochner, S. \& Furnham, D (2001) The Psychology of Culture Shock, $2^{\text {nd }}$ edn. Routlegde UK

Yigitcanlar, T., Mayere, S., McCartney, R., and Mohamed, M.Z., (2009) 'Providing innovative planning education experience: teaching regional planning in an international context' Proceedings of the ANZAPS Conference, 28-30 August 2009, Brisbane

\footnotetext{
${ }^{1}$ Despite English being the medium of university education in Sri Lanka, for most students this is a second language. Most Sri Lankan students are trained in British or American English, often as heard from media such as $\mathrm{CNN}$ or BBC.
} 